\title{
Practice of Flexible Teaching on Computer Specialized Courses
}

\author{
Wei Chen* \\ Department of Information Engineering, Environmental Management College of China, \\ Qinhuangdao,China \\ fallfall@126.com
}

Keywords: Higher Vocational Education; Personnel Training; Teaching Reform; Flexible teaching; Specialized Courses

\begin{abstract}
According to the basic idea of higher vocational education teaching reform and requirements for modern personnel training, in view of the current higher vocational computer specialized teaching process, in flexible teaching of computer specialized course has been discussed thoroughly, and implemented in the teaching practice. The teaching reform practice results proves that flexible teaching in training high level and comprehensive ability of professional talents has far-reaching significance.
\end{abstract}

\section{Introduction}

The aim of higher vocational education is to develop pragmatic professionals with high-quality and professional skills. With our country's industrial structure adjustment and the in-depth reform, the personnel market has new requirements for the pragmatic professionals, and meanwhile, with the popularization of higher vocational education development, the difference of the learning interest and learning needs is of the increasingly obvious for the diversity and the individuation of student populations. On the other hand, the employment situation is serious and the career development direction is more and more comprehensive with the cross and fusion of disciplines and knowledge. Traditional rigid teaching model ${ }^{[1]}$ is difficult to deal with the situation about different learn basic of higher vocational students, strong personality development requirements and varied demand of job group, it is difficult to cultivate the students' innovation spirit and innovation ability, and then it requires the teaching model of higher vocational education must be reformed, which takes the path of the flexible teaching model.

\section{Flexible teaching and its requirements}

Flexible teaching is a new teaching method in the guidance of flexible education theory. Flexible education $^{[2]}$ is aimed to meet the objective requirements of continuous development and change of science and technology and economy, and cultivate students' adaptability in the future. It is more combinatorial, optional, and sustainable in some aspects, such as teaching plan, teaching content, teaching management, teaching methods, and so on.

Flexible teaching is a dynamic teaching ${ }^{[3]}$. It requires that teachers should adjust course content according to the social demand and personality development of students, and aim at stimulating students' learning potential effectively. It requires that teachers should provide diverse teaching needs, arrange different teaching contents, set the appropriate teaching goal and the way of evaluation, and let different students study at their own pace to accomplish their own learning goals, according to the needs of students, students' learning situation, and the teaching requirements of different levels of students. It requests that the teacher should write teaching plans according to the practical teaching, 
provide students with flexible and varied teaching methods so as to arouse the enthusiasm of students fully and create a good learning environment and atmosphere, make the students in the teaching process from passive recipients of knowledge into active learners, then cultivate students' good learning methods, creative self-regulated learning ability and the ability to adapt to changes in jobs ${ }^{[4]}$.

According to the basic principle and requirements of flexible education, combining with the teaching practice of computer specialized courses, the teaching of computer specialized courses are reformed, flexible teaching is implemented, and the good teaching results are achieved.

\section{The implementation of flexible teaching in the teaching of computer specialized courses}

The computer specialized is mainly to cultivate students' logical thinking, basic computer software operation ability, the ability of program design and system development. Computer specialized courses have the characteristics of strong theoretical, practical and developed rapidly. Due to students' varied learning foundation and hobbies, for computer specialized courses there are also different preferences. Most students don't like boring theory knowledge. For practice part of the program design and system development, some students don't know where to start or not interested, the subsequent application is no longer considered when the course is over. In order to improve the condition, flexible teaching in the teaching process is carried out.

Dynamic teaching content-graded modular teaching. According to specialized and work requirements, in the teaching process, teachers reorganize the teaching content, and divide them into several independent teaching module each of which corresponds to a work process based on the post actual demand. Then teachers organize teaching in module for unit, mix theory into skills training of each module, grade the students according to the condition of students and the basic of learning, and arrange different teaching objectives and teaching tasks for different levels of students.

For example, in the course "analysis and design of application system", students can be divided into two levels, we require that low level students can connect the actual case of code given by teachers together, and the code can be debug successfully after small amount of error correction. And we require that senior students can implement other system development independently, following teachers' actual case, including requirements analysis, database construction, programming, debugging and running.

At the same time, in addition to the sufficient preparation before class, teachers should master teaching plan flexibly in the process of teaching, adjust and update teaching content according to the dynamic response of students' acceptance and the latest development, teachers also should constantly update their professional knowledge, so as to mobilize the curiosity of students actively, broaden the students' thinking.

Interactive class teaching. Teaching is a process of two-way interaction between teachers and students ${ }^{[5]}$. In the process, teachers play a leading role, and the dominant position of students should also be reflected. Teaching" and "learning" of the teaching content have reasonable interaction, The class teaching should be designed so as to arouse the enthusiasm of students learning fully, stimulate students' interest in learning, and transform passive learning into active learning.

Teachers can guide students to active learning using actual cases or interesting cases in life ${ }^{[6]}$. For example, in the course "secondary development of GIS", teachers demonstrate the map and bus query system for students firstly, so that students are interested in implement the map query themselves. The organization of teaching content, both the theoretical knowledge, and practical cases are included, and the introduction of the case should start from the actual needs, combine the theory with the actual project cases, so as to let the students know the application value of the learning content, further stimulate interest. 
The varied counseling. Counseling ${ }^{[7]}$ can solve the difficulty of knowledge for students in time, make teachers understand the status and needs of the students, and lay a good foundation for the next step in the teachers' teaching, so as to enhance teaching effect.

(1)Collective counseling

Collective counseling is a way of the interpretation which requires teachers to simulate the thinking of students, guide students to find out the cause of the error, inspire students' thinking, and discuss the solution, in order to deepen the understanding and mastering of knowledge.

(2)Individual counseling

Individual counseling should solve students' problems according to different learning needs of students, and also should pay attention to guide correct learning idea, analysis process and the application ability of students.

(3)Students counseling group

In the teaching process, we should choose students of mastering knowledge better to form the counseling groups, so as to help teachers tutor other students. In this way, students can improve their learning enthusiasm, and learn actively.

(4)Counseling online

The class teaching time of a course is limited, so there may be a lot of problems which can not be solved in time, and then we can counsel online such as establishing class QQ group, chat-room, or email. Counseling online can be a good way to cover the shortage in the time and place.

Open experimental teaching . In the open experimental teaching process ${ }^{[8]}$, students can choose experiment content of the project and time independently according to their course schedule and plan. When students choose experiment content of the project, they will think the methods and steps by themselves, go through all related reference material and discuss each other, in order to improve the application ability of knowledge, the ability of independent thinking and studying, and the ability of innovation. The process requires teachers to guide the right direction for content chosen by students, coordinate and deal with various problems.

Self-regulate network learning. With the rapid development of network, the network technology integrated into the concept of modern education has become the essential means to make up for the limited class teaching. Teachers are designers of teaching and initiators of knowledge, as well as providers and administrators of teaching resource. Teachers will put all of the teaching resources in web site, in order to let students choose learning content needed for self-regulated learning in network learning environment ${ }^{[9]}$.Course network learning environment is shown as Fig. 1.

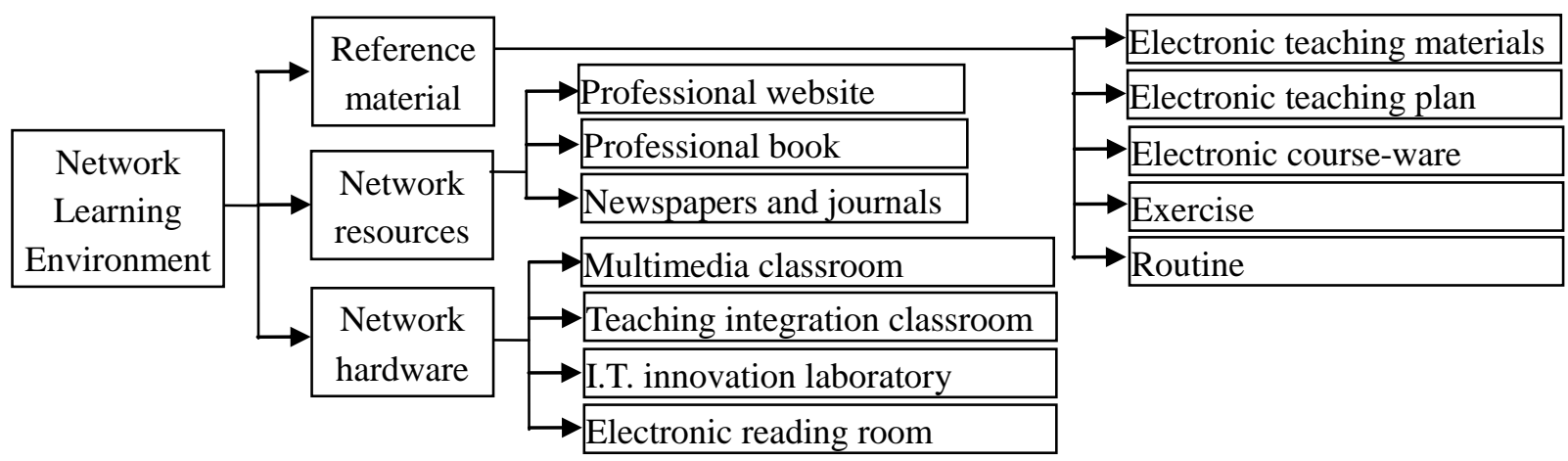

Figure. 1 Course network learning environment

Multivariate evaluation . Evaluation ${ }^{[10]}$ is an important part in teaching work. Evaluation can not only reflect students' academic record, but also discover and cultivate the students' potential. Scientific evaluation system can arouse the enthusiasm of students, promote the all-round development of students, enhance the quality of self-confidence and improve the ability of innovation. 
Evaluation in computer specialized courses is an integration of the evaluation mechanism, which includes the usual results, theory test, exam on computer, course practice, and course paper. The final result combines with attendance result, ordinary point, the final result, self-evaluation result and the self-assessment result.

\section{Conclusions}

In this paper, the teaching reform of computer specialized courses is discussed, and flexible teaching is introduced. Through the actual teaching experiment, it is proved that flexible teaching can motivate students' interest in learning, cultivate students' good learning methods, improve the student practical ability and innovation ability, and promote the cultivation of innovative professionals. The teaching reform effect is good. Of course, it is necessary to continue to carry on the teaching continually in order to found out the more suitable teaching methods of computer specialized course.

\section{Acknowledgments}

This work is supported by the education planning program of humanities and social science research of institutions of higher learning in Hebei Province under Grant NO.GH132083, the project of higher education scientific research of Higher Education Institute of Hebei Province under Grant NO.GJXH2013-127, science and technology bureau of Qinhuangdao Grant NO.201302A294, 201302A297 and the project of environmental management college of China Grant NO.2014037.

\section{References}

[1] LIU Shui-guo, LIU Xin-ying. Construction and Analysis of Flexible Teaching Management Model. J. Vocational \& Technical Education Forum. 26 (2012) 67-68.(In Chinese)

[2] ZHOU Hui, CAO Li-hua. Thought of flexible teaching in higher vocational electrical and mechanical professional. J. Nanchang Junior College. 2 (2012) 157-158+172.(In Chinese)

[3] SHAN Xiao-yan, LIN Lin. Research on Construction Schema of Self-learning Platform Based on Web3.0. J. Continue Education Research. 12 (2010) 163-164.(In Chinese)

[4] ZOU Cheng. Stratification Modular Teaching of Higher Vocational Mathematics. J. Simao Teachers' College. 1 (2012) 137-140.(In Chinese)

[5] CAO Er-ling. Exploration on Flexible Teaching Pattern in Colleges and Universities. J. Xingtai Polytechnic College. 4 (2008) 19-21.(In Chinese)

[6] PEI Yan. Application of Flexible Management in the University Teaching Management. J. Course Education Research. 2 (2014) 14.(In Chinese)

[7] LIU Yan, SUN Qi-guo. Teaching Reform on Flexible Management of university .J. Beijing Education. 2 (2013) 61-62.(In Chinese)

[8] YUAN Ling-ling, MEI Wen-tao. Research and Application of Flexible Teaching Management System Based on the Project. J. Tianjin Vocational Institutes. 8 (2013) 109-111.(In Chinese)

[9] LIU Shui-guo, LIU Xin-ying. Design and Implement of Web Based Network Teaching Platform. J. Vocational \& Technical Education Forum.. 26 (2012) 67-68.(In Chinese)

[10]QIN Chang-gui. The Implementation of Flexible Education in Higher Vocational Education. J. Xingtai Polytechnic College. 2 (2011) 62-63+67.(In Chinese) 